\title{
Review
}

Neuro epidemiology

\section{Early Life Epidemiology of Alzheimer's Disease - A Critical Review}

\author{
Alon Seifan $^{a}$ Matthew Schelke ${ }^{b}$ Yaa Obeng-Aduasare ${ }^{a}$ Richard Isaacson ${ }^{a}$ \\ ${ }^{a}$ Alzheimer Prevention Clinic and Memory Disorders Program, Department of Neurology Weill Cornell Medical \\ College, ${ }^{b}$ Weill Cornell Medical College, New York, N.Y., USA
}

\section{Key Words}

Alzheimer's disease $\cdot$ Early life $\cdot$ Dementia $\cdot$ Development

\begin{abstract}
Background: As adult brain structure is primarily established in early life, genetic and environmental exposures in infancy and childhood influence the risk for Alzheimer disease (AD). In this systematic review, we identified several early life risk factors and discussed the evidence and underlying mechanism for each. Summary: Early risk factors for AD may alter brain anatomy, causing vulnerability to AD-related dementia later in life. In the perinatal period, both genes and learning disabilities have been associated with the development of distinct $A D$ phenotypes. During early childhood, education and intellect, as well as body growth, may predispose to AD through alterations in cognitive and brain reserve, though the specific mediators of neural injury are disputed. Childhood socioeconomic status (SES) may predispose to AD by influencing adult SES and cognition. Association of these risk factors with underlying AD pathology (rather than just clinical diagnosis) has not been sufficiently examined. Key Messages: Factors that impede or alter brain growth during early life could render certain brain regions or networks selectively vulnerable to the onset, accumulation or spread of AD-related pathology during later life. Careful life-course epidemiology could provide clues as to why the brain systematically degenerates during $A D$.

(c) 2015 S. Karger AG, Basel
\end{abstract}

(c) 2015 S. Karger AG, Basel

0251-5350/15/0454-0237\$39.50/0

\section{Introduction}

Adult brain structure is primarily established in early life [1] and is a major determinant of an individual's susceptibility to Alzheimer disease (AD) [2]. By altering both the anatomical (number and connectivity of neurons) and functional (ability to engage alternative brain networks) organization of the adult brain, early life exposures influence the vulnerability of brain regions to $\mathrm{AD}$ pathology and the ability of the brain to compensate in the presence of disease [3]. Because AD is diagnosed clinically long after early life and the onset of pathology, the links between early exposures, premorbid brain structure and $\mathrm{AD}$ pathology and symptomatology remain unclear.

Prior reviews have proposed a developmental basis for $\mathrm{AD}[2,4-8]$, and recent studies demonstrate evidence of atypical neurodevelopmental trajectories in people at genetic risk for $\mathrm{AD}[9,10]$ and in people diagnosed with a variant of progressive aphasia (logopenic primary progressive aphasia (PPA)) associated with AD pathology [11]. Here, we focus specifically on human epidemiological studies in English that have used incident AD as the primary outcome and excluded studies that used general or all-cause dementia as the outcome measure. Specifically, we discuss the impact of education and intellect, childhood socioeconomic status (SES), body growth, childhood adversity, learning disabilities and genetics on late-life $\mathrm{AD}$ risk in the context of brain structure and development (table 2 ; fig. 3 ). We suggest that the mecha-

\section{KARGER 125}

E-Mail karger@karger.com www.karger.com/ned
Alon Seifan, MD, MS

Alzheimer Prevention Clinic and Memory Disorders Program Department of Neurology Weill Cornell Medical College 428 East 72nd Street, Suite 500, New York, NY 10021 (USA)

E-Mail als9122@med.cornell.edu 
Fig. 1. Models of early-life risk factors for

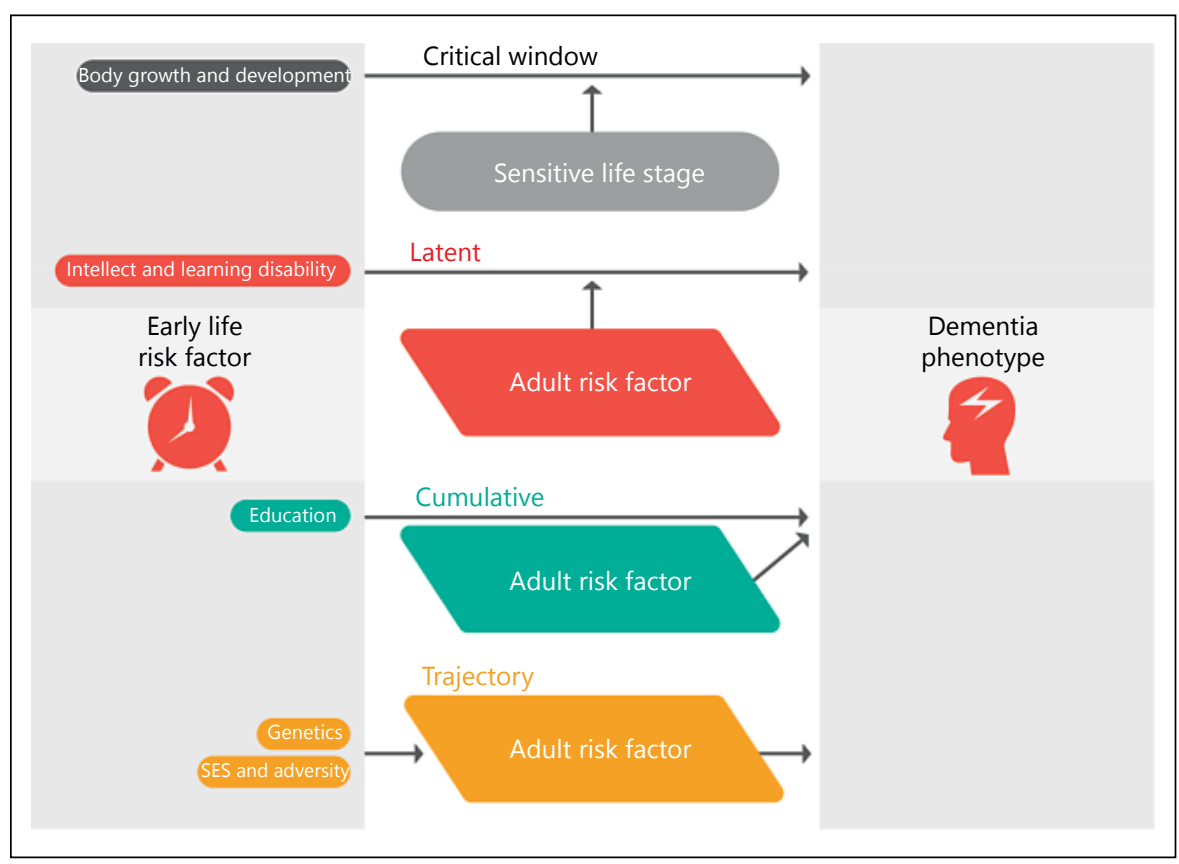

nisms of these risk factors are best characterized by 4 models - critical period, latent, cumulative and trajectory [12] - that describe the effects of early exposures as timing-specific, clinically unmasked by a stressor later in life, accumulated over time or determinant of later pathways, respectively (fig. 1). Considered in the context of adult brain connectivity that was finally deciphered, these models offer a unified conceptual framework linking early social and biological conditions, premorbid brain structure and ultimate susceptibility or resilience to AD.

We discuss the findings in the context of the hypothesis that genetic and environmental factors that cause atypical brain development may lead to an adult brain that is more susceptible to neurodegenerative pathology in later life. Ultimately, increased awareness of the early life factors associated with risk for AD could lead not only to a better understanding of the causes of $\mathrm{AD}$ but also to earlier identification of at-risk individuals and more timely access to future preventative interventions.

\section{Materials and Methods}

References for this review were identified by searches of PubMed between March 1970 and October 2014, including references from relevant articles. The following search terms and their synonyms were used to identify the initial list of abstracts: Alzheimer disease, childhood, socioeconomic status, adversity, nutrition, head circumference, stature, arm length, leg length and

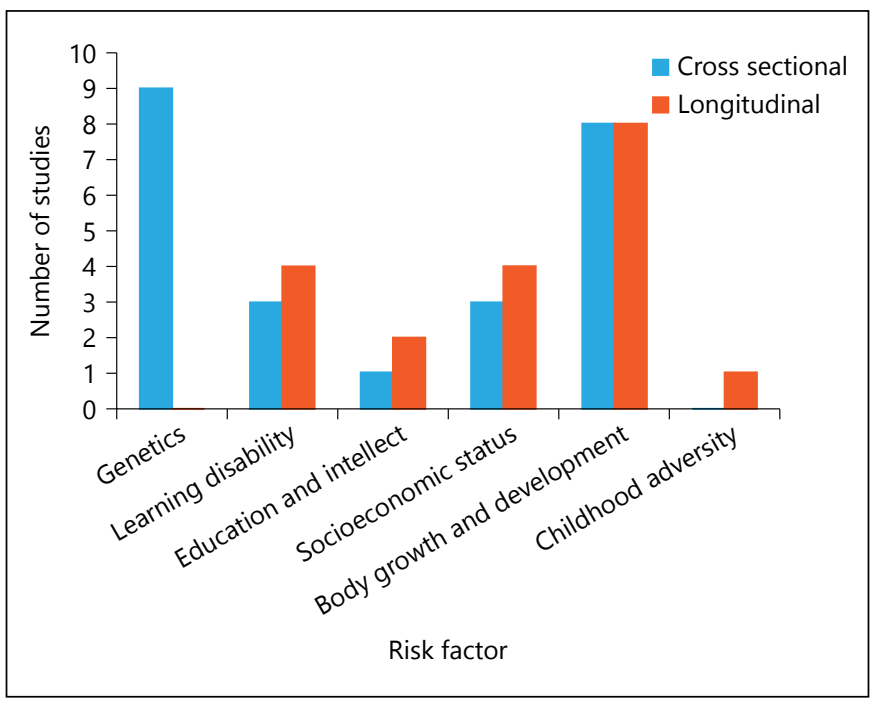

Fig. 2. Histogram showing number of included studies assessing early-life risk factors.

learning disability. We searched for articles published in English between January 1, 1970 and December 31, 2014. These terms were drawn from previous reviews of the literature on early life epidemiology of cognition $[2,8]$. Of the 2,711 abstracts initially identified as potentially relevant, a total of 436 were selected for review of the full article. Of the 436 full articles reviewed for this study, a total of 43 were selected for final inclusion (fig. 2). We only included studies of late-onset $\mathrm{AD}$, as the early onset form has a different molecular pathogenesis and is likely affected by different 
risk factors. Studies in which the primary outcome included final adult cognition but not AD diagnosis were not included. Studies in which the primary outcome included episodic memory difficulty and/or decline were retained in the final list because the most common cause of episodic memory trouble in later life is AD.

\section{Results}

Myriad cross-sectional and longitudinal epidemiological studies were identified linking early life factors to adult brain structure and AD risk, including a few studies in which pathology-supported criteria were used for AD diagnosis. Table 1 lists the characteristics of each study in further detail. Below, we discuss the studies in order of risk factor and classified by the study design.

\section{Genetics}

Genes are major determinants of brain development and adult neuroanatomy and modify the risk for AD later in life. Many studies have shown that brain network structure and function develop differently during early childhood and adolescence in individuals with genetic risk for $\mathrm{AD}$, particularly carriers of the late-onset risk genes $A P O E 4$ and SORL1 $[9,10]$. Infant carriers of APOE4 develop less white and gray matter volume during the first 3 years of life than non-carriers in temporal, parietal and cingulate regions that are preferentially affected by AD [9]. Similarly, the left entorhinal cortex is significantly thinner in healthy children and adolescents carrying APOE4 compared to non-carriers [13] and symptomatic APOE4 carriers have smaller hippocampi, with differences most pronounced prior to the age of 65 years [14]. In young healthy adults, $A P O E 4$ is also associated with abnormal white matter microstructure and with reduced posterior cingulate mitochondrial activity, without differences in soluble or insoluble amyloid [15]. Remarkably, APOE4-positive children with a family history of AD show impairment on tests of reading and language, suggesting that the early structural changes from APOE4 may cause functional impairment long before $\mathrm{AD}$ pathology begins [16]. Together, these findings indicate that the presence of the APOE4 allele significantly reduces cortical volume and connectivity in a distributed network later affected by $\mathrm{AD}$ and may impair cognition throughout the lifespan of the patient.

Other genetic elements may also alter brain anatomy and contribute to AD risk. Mutations in the APOE receptor, SORL1, have also been linked to late-onset $\mathrm{AD}$ and alter neural structure in AD-affected networks [17]. SORL1 variant children show white matter microstruc- tural abnormalities, and the underexpression of SORL1 mRNA in brain occurs specifically during childhood and adolescence [10]. Similarly, SORL1 polymorphisms, including the AD-associated single nucleotide polymorphism rs668387, were also associated with reduced hippocampal volume in a 936 healthy Caucasian young persons aged 18-36 years [18]. Although late-onset AD genes like APOE4 and SORL1 have been the focus of most studies, the early-onset AD genes presenilin 1, presenilin 2 and amyloid precursor protein are also neurodevelopmental genes that may cause similar abnormalities [19, 20]. Consistent with a trajectory model, AD-associated genetic and epigenetic alterations contribute not only to the molecular pathology of AD but also cause aberrant structural and functional development that may make the brain anatomically susceptible to AD.

\section{Childhood Intellect and Learning Disabilities}

Here, we discuss studies of innate intellect or learning disabilities, as opposed to educational levels, and late-life AD risk. Higher education has been consistently associated with reduced risk for $\mathrm{AD}$ in many cross-sectional and longitudinal studies, and 2 recent meta-analyses found that the incidence of $\mathrm{AD}$ is inversely proportional to level of education $[21,22]$. Full discussion of this extensively studied topic [3] is beyond the scope of this review, and thus studies on education and $\mathrm{AD}$ risk were not included in the final list of studies, but the mechanisms of the protective effects of education are discussed in the discussion section in the context of childhood SES.

Native intelligence may influence risk for AD. In a population-based, case-control study, participants rated their childhood school performance; 'below average' performance was correlated with a 4 -fold higher incidence of AD [23]. Similarly, 2 longitudinal studies of adolescent handwritten memoirs from cloistered nuns found that lower idea density in the memoirs predicted greater neurofibrillary tangle and senile plaque pathology at autopsy and an increased incidence of clinical diagnosis of $\mathrm{AD}[24,25]$. There was no association between grammaticality and AD, indicating that the effect of idea density on $\mathrm{AD}$ pathology is unrelated to general writing ability developed in school.

For people with atypical neurodevelopmental trajectories, developmental or acquired alterations in the language network may lead to selective vulnerability of the language cortex to neurodegenerative pathology in later life [26]. Four studies have examined the association of developmental learning disabilities and specific types of dementia, particularly the atypical AD variant of logopenic PPA. Logopenic PPA from AD has the same molecu- 


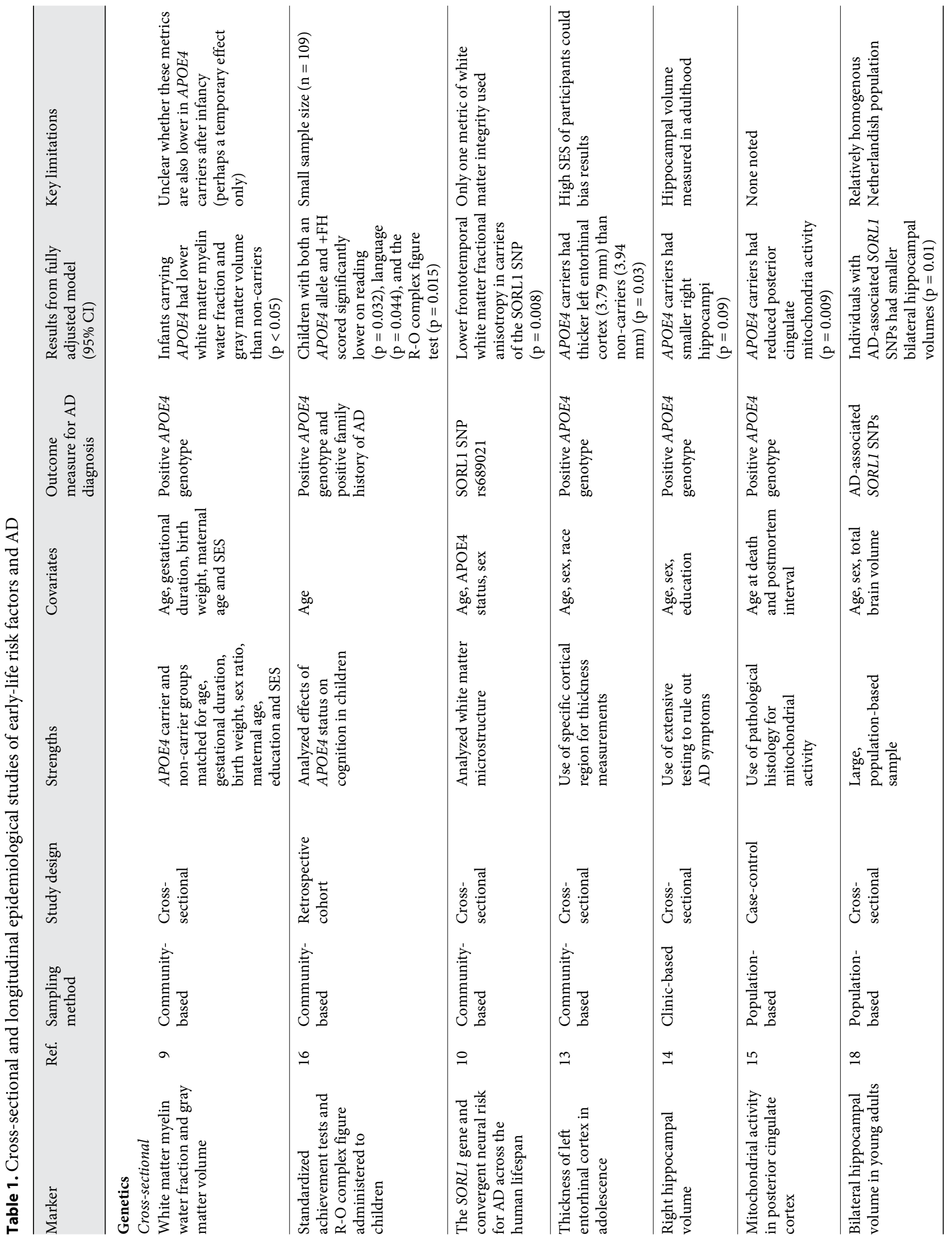




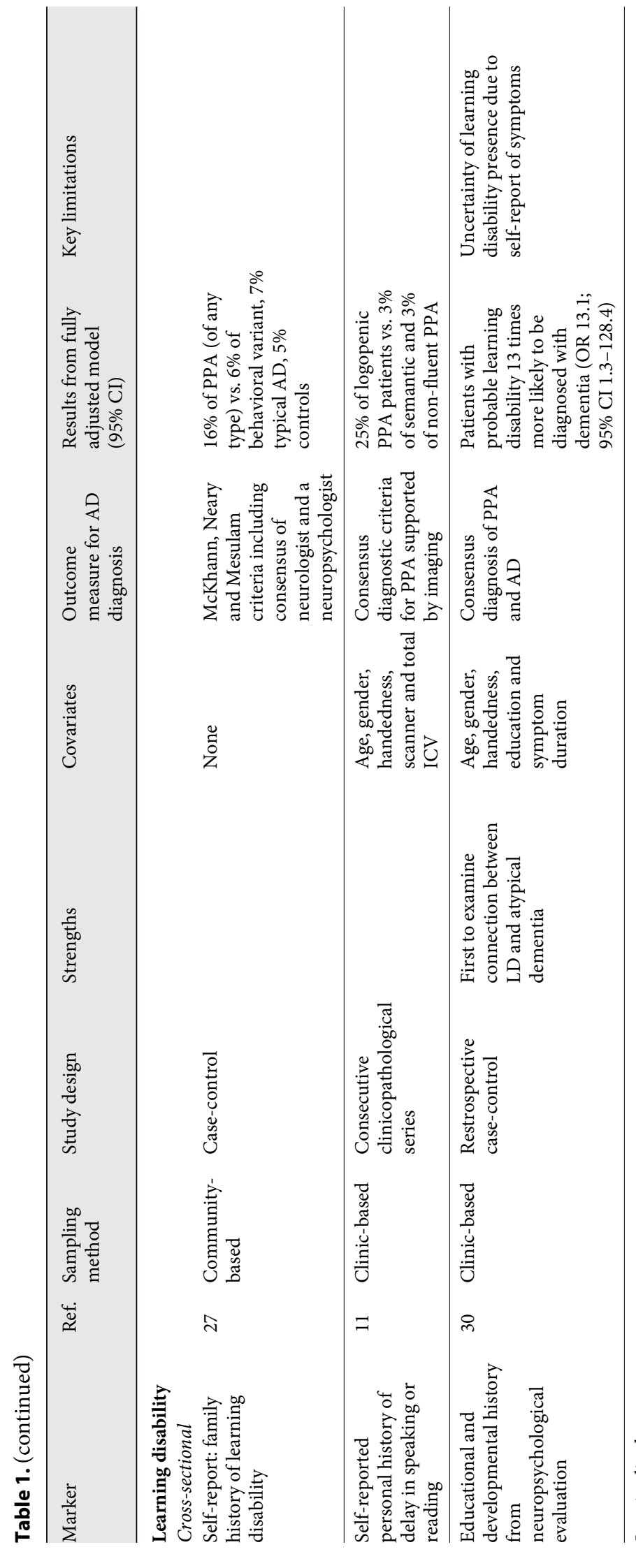

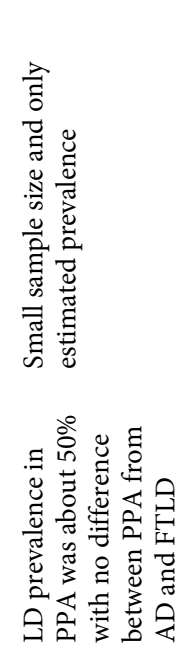

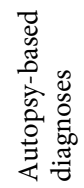

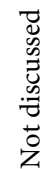

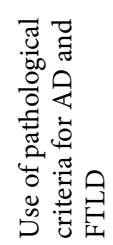

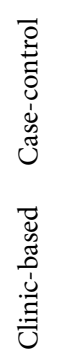

สิ

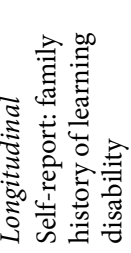

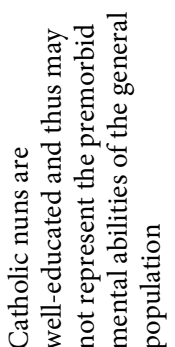

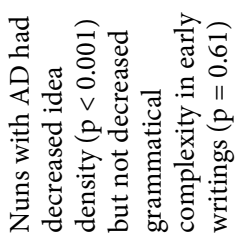

동

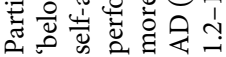

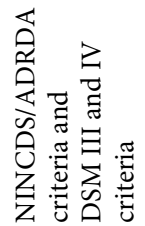

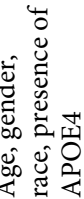

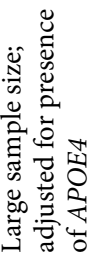

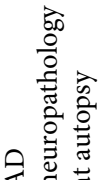

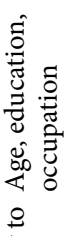

额

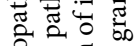

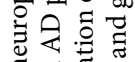

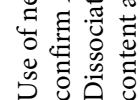

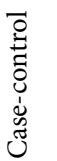

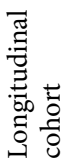

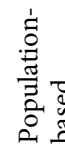

$\pi$

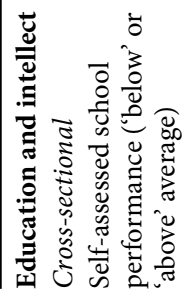

竞

$\stackrel{4}{4}$

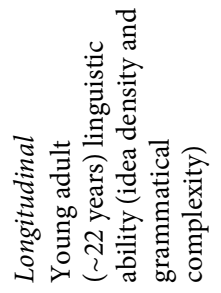




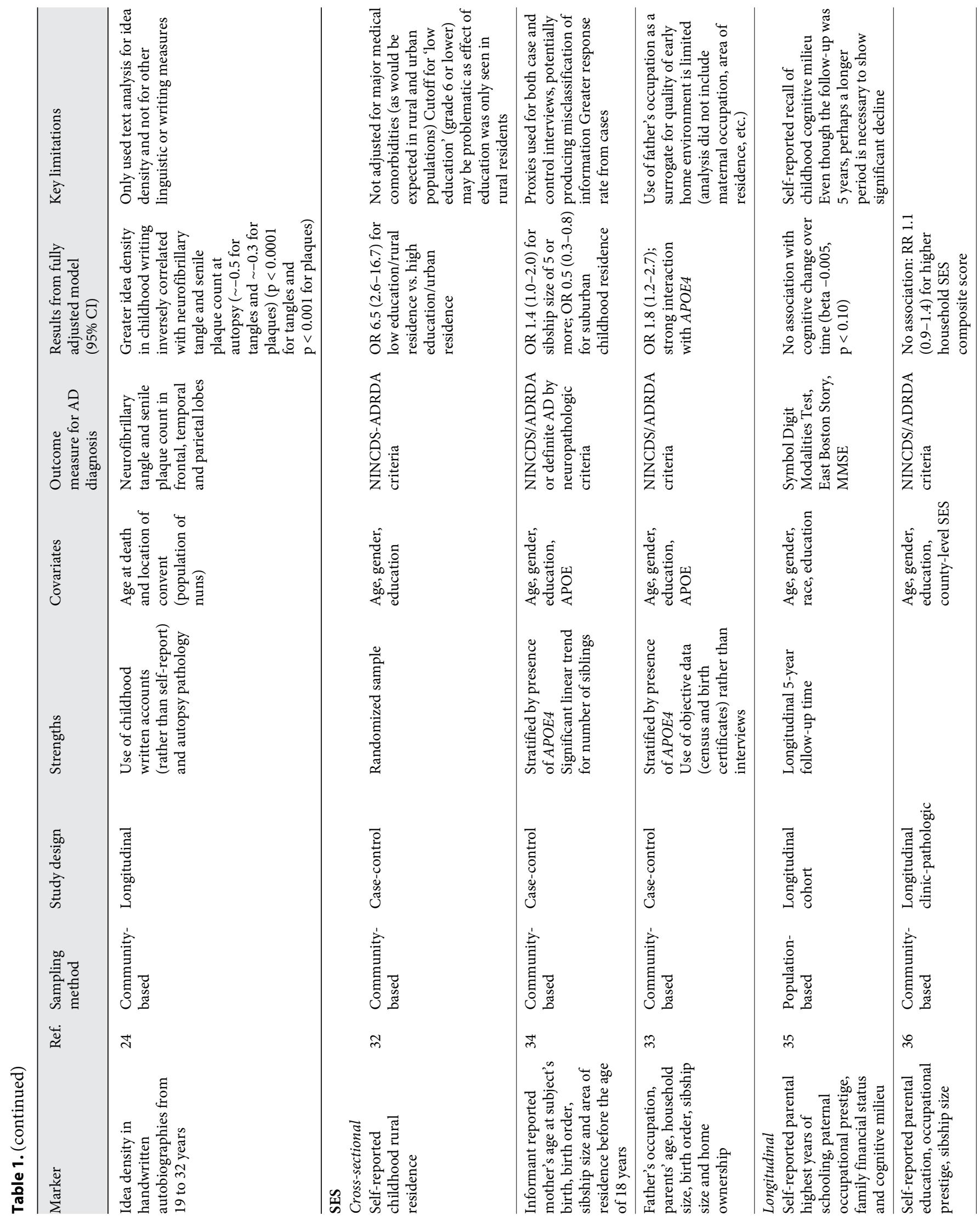




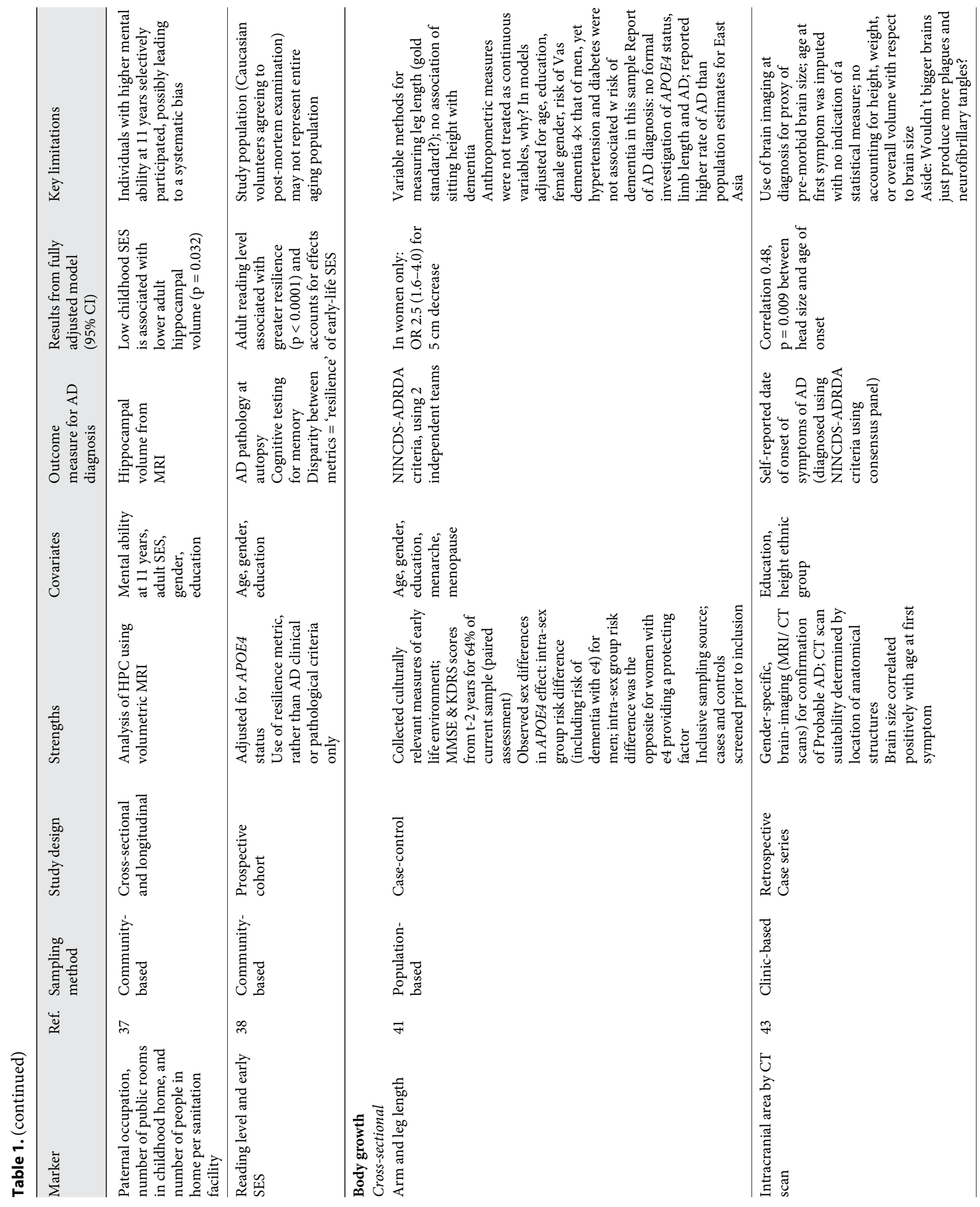




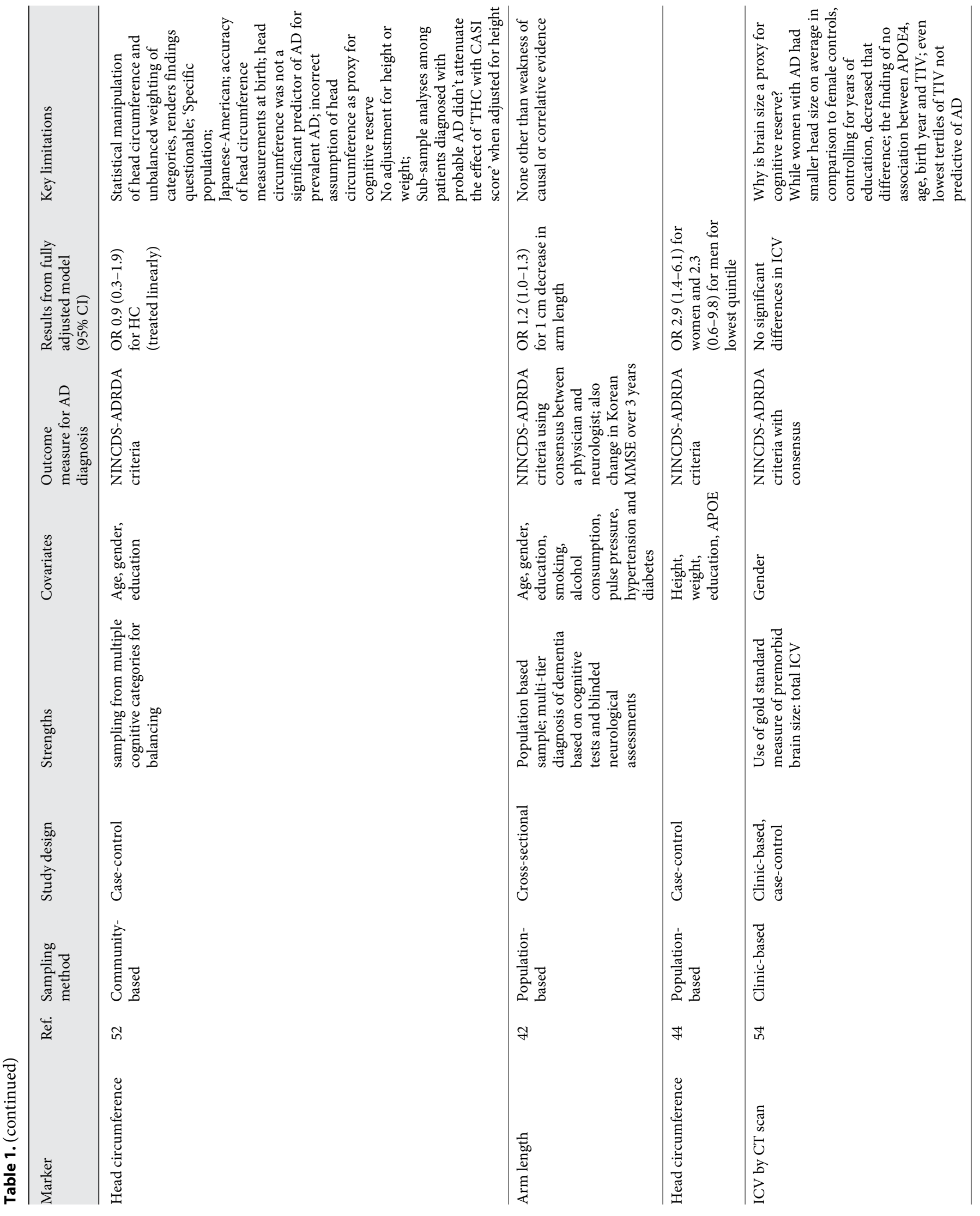




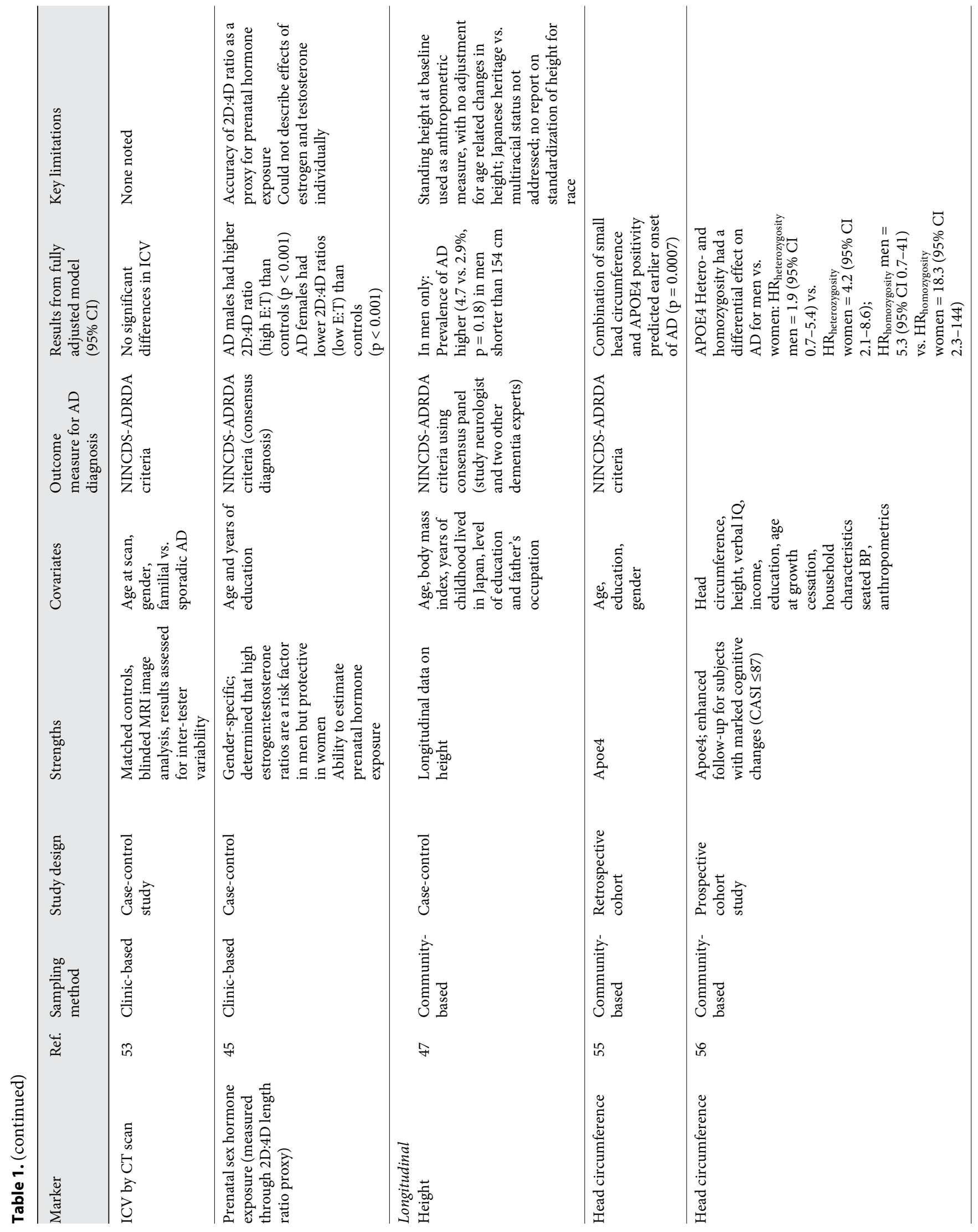




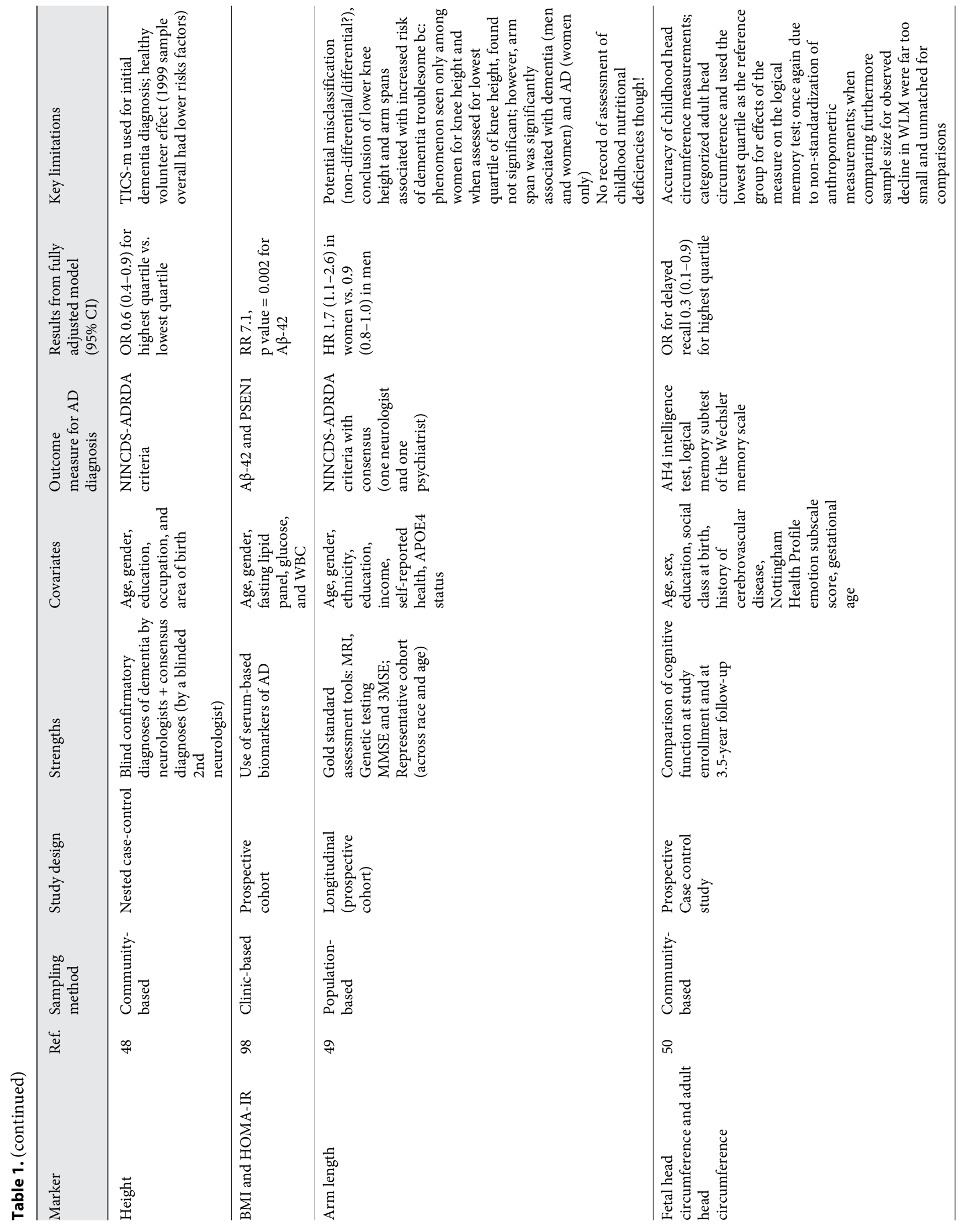




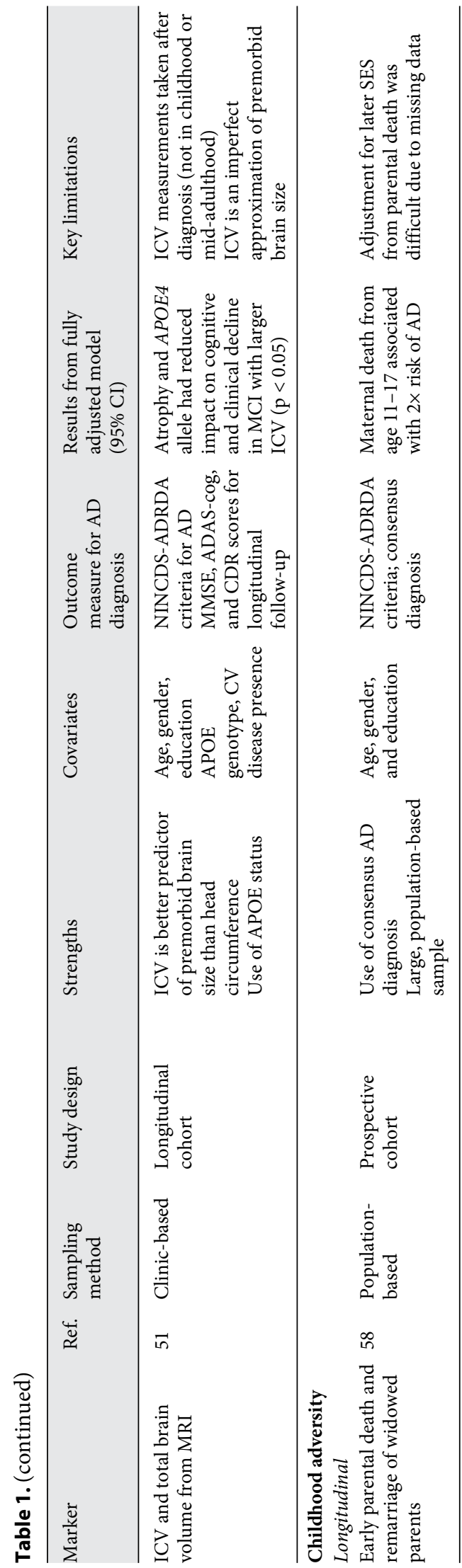

Early Life Epidemiology of AD lar pathology as hippocampal ('typical') $\mathrm{AD}$ and is affected by the same early life risk factors; we discuss it specifically in this section because a history of learning disability appears to predispose individuals not just to $\mathrm{AD}$ pathology but also to the unique anatomical involvement and clinical presentation seen in logopenic PPA from AD.

\section{Cross-Sectional Studies}

In a study of over 600 subjects from the Northwestern Alzheimer's Disease Center registry, $16 \%$ of the 108 individuals with PPA (of any type) and $32 \%$ of their first-degree family members answered affirmatively to having a history of learning disability [27]. These frequencies were significantly higher than those noted in control subjects without $A D$, subjects with typical amnestic $A D$ and subjects with behavioral variant frontotemporal lobar degeneration (FTLD). Among the families of PPA probands, remarkable clusters of learning disabilities, particularly developmental dyslexia, were noted.

A second study used a more specific breakdown of the type of PPA, with imaging-supported classification [11]. Specifically, $8 \%$ of all PPA subjects from the University of California San Francisco Memory and Aging Center had made self- or informant-based reports about a personal history of delay in speaking or reading at baseline medical interview. This was driven by a particularly high prevalence $(25 \%)$ in the 48 subjects with logopenic PPA. This finding is important because although logopenic PPA is often caused by underlying FTLD pathology, it is frequently associated with $\mathrm{AD}$ pathology [28]. Logopenic PPA subjects with learning disability were younger at onset and showed atrophy in the areas affected by developmental dyslexia (posterior middle and superior temporal gyri).

The authors of the initial study demonstrating higher rates of self-reported LD in people with PPA recently published a follow-up study using pathology-supported diagnoses to attempt to address the question of whether PPA patients reporting prior $L D$ in fact had AD or FTLD pathology. The results showed that both AD and FTLD pathology were represented equally in the PPA patients reporting childhood $\mathrm{LD}$, suggesting that the relationship between LD and neurodegenerative disease is not specific to neurodegeneration due to $\mathrm{AD}$ [29]. One major caveat is that this study used family history as the proxy for LD; although LD does run in families, a family history of LD does not equate with a personal history of LD.

Finally, our group recently compared the frequency of self-reported learning disabilities in 68 typical $\mathrm{AD}$ cases vs. 17 atypical $A D$ cases (posterior cortical atrophy (PCA), logopenic PPA and dysexecutive AD); we demonstrated 
a 13-fold higher risk of self-reported LD in the atypical group, after adjusting for demographics and disease severity [30]. The type of learning disability was different for PPA vs. PCA cases.

In summary, native intellect, including atypical neurodevelopment as seen in learning disabilities, likely predisposes either to $\mathrm{AD}$ risk/resilience or to atypical phenotypes of $\mathrm{AD}$. The factor(s) that determine which people with learning disabilities develop atypical dementias remain unknown. However, it is striking that the types of learning disabilities may in fact segregate with subtypes of $\mathrm{AD}$ phenotypes; this would be consistent with the latent model in which early changes in a specific anatomical region predispose to $\mathrm{AD}$ pathology in that region, rather than serving as a systemic risk factor.

\section{Early-Life SES}

Several studies have examined the association between early-life SES and incidence of late-life AD; markers of early-life SES include place of birth, literacy and education, sibship size, birth order and parental occupation and education. Though multiple studies agree that a lower early-life SES is associated with reduced late-life cognitive ability, evidence for an association with late-life $\mathrm{AD}$ is equivocal. In general, SES would be expected to influence late-life AD risk via a social trajectory model as early SES has a major impact on adult health and cognition [31].

\section{Cross-Sectional Studies}

Various cross-sectional studies have reported that early residence, parental occupation and sibship size increase risk for $\mathrm{AD}$, though these factors interact with education level and the APOE4 genotype. In 2,212 African Americans who are 65 years of age or older drawn from a community-based prevalence study of $\mathrm{AD}$ from 29 census tracts in Indianapolis, the combination of living in a rural residence and having less than 6 years of schooling had the strongest effect size in increasing risk for $\mathrm{AD}$ [32]. The authors concluded that low education serves as a marker for other factors related to low SES that may increase risk for $\mathrm{AD}$ in later life. In a case-control study of over 700 participants of the Genetic Differences in AD study from the University of Washington Alzheimer's Disease Patient Registry, subjects with a higher sibship size or a father in a manual occupation had a higher risk for $\mathrm{AD}$ but the effect was only significant in the presence of APOE4 [33]. In a community-based, case-control study of over 700 individuals recruited from a health maintenance organization in the Seattle region, area of residence before the age of 18 years and number of siblings were associated with clinical or pathological diagnosis of $\mathrm{AD}[34]$.

\section{Longitudinal Studies}

In contrast to the cross-sectional studies demonstrating possible links between childhood SES and AD risk, 2 longitudinal studies with approximately 5-6 years of follow-up showed associations between early life SES and overall late-life cognitive capacity but not rates of $\mathrm{AD}$ dementia $[35,36]$. In a population of Chicago adults, a combined measure of parental education, occupation and financial status showed a small but significant association with cognitive testing at 65 years of age or older in a population of Chicago adults [35]. In a study of Catholic clergy members, the SES of the participants' birth county and household correlated with late-life cognitive function; however, there was no association with the development of $\mathrm{AD}$ in either study [36].

Early SES may influence late-life cognitive function through its effects on adult brain anatomy and cognition. Individuals with lower childhood SES have smaller hippocampi by volumetric MRI [37], and one prospective cohort study demonstrated that higher adult reading level predicted a larger discrepancy between evidence of AD at pathology and late-life cognitive testing and thus greater resilience to AD [38]. Reading level accounted for the effects of early life SES, implying that the effect of childhood SES on clinical AD may be mediated indirectly through adult cognition.

Together, these studies suggest 3 conclusions. First, some studies have demonstrated a link between childhood SES and late-onset AD, though other results are inconsistent. Second, APOE4 status and other biological risk factors may be critical determinants of the effects of early SES on AD risk. Finally, early SES has been consistently shown to be associated with cognition, brain anatomy and SES in adulthood; any effects of early SES on later $\mathrm{AD}$ may thus be mediated through the adult milieu consistent with a trajectory model [39]. The potential relationship between early-life SES and pathologically defined $\mathrm{AD}$, partly addressed in only one study [34], requires further exploration.

\section{Body Growth and Development}

Of all the childhood risk factors for $\mathrm{AD}$, early-life body growth has been studied most extensively. Adult anthropomorphic measures of early-life body development such as leg length, height, head circumference and digit ratios are markers of early-life nutrition influenced by a host of 
early environmental factors, including hormonal exposure, and have been associated with late-life cognitive outcomes including clinical diagnoses of AD. As optimal body and brain development is achieved during specific periods of childhood and adolescence [40], the effects of body growth on brain size, cognitive reserve and ultimate symptomatology of $\mathrm{AD}$ are best described with a critical window model.

\section{Cross-Sectional Studies Included in the Analysis}

Most cross-sectional studies suggest that smaller cranial and body measurements are associated with increased risk for $\mathrm{AD}$. In 746 Koreans aged 65 years or above, shorter arm and leg length were independently associated with clinical diagnosis of both vascular dementia and $\mathrm{AD}$, but only in women [41]; in a similar sample, arm length but not body height was associated with cognitive function and clinical diagnosis of $\mathrm{AD}$ dementia in both genders [42]. In a convenience sample of 28 women with clinical diagnosis of 'probable $\mathrm{AD}$ ' attending an outpatient memory disorder clinic in New York, lower intracranial area measured on CT scan in adulthood was associated with earlier age of onset of symptoms [43]. In a large, ethnically diverse, population-based sample from the Northern Manhattan Aging Project, subjects in the smallest quintile of head circumference had a higher risk for prevalent probable or possible AD [44]. Head circumference was not associated with educational attainment or premorbid cognitive capacity. Interestingly, in a small study of 20 adults diagnosed with $\mathrm{AD}$ and 20 controls, digit ratio - a marker of prenatal testosterone and estrogen exposure - was associated with $\mathrm{AD}$ risk, with opposite patterns for males vs. females (higher digit ratios in $\mathrm{AD}$ males and lower digit ratios in $\mathrm{AD}$ females) [45]. Finally, high childhood body mass index and concomitant insulin resistance increases circulating levels of the $\mathrm{AD}$ associated proteins amyloid-beta 42 and presenilin-1, suggesting a molecular link between childhood metabolism, body measurements and late-life AD [46].

\section{Longitudinal Studies}

Results from the longitudinal studies largely agree with those of the cross-sectional studies. Two studies have associated shorter body height with increased incidence of AD: the Honolulu Asia Aging study found that $A D$ was significantly more common in men 61 inches or shorter in over 3,000 Japanese men [47], and the Israeli Ischemic Heart Disease Study found increased risk of $\mathrm{AD}$ in individuals with shorter stature [48]. Other longitudinal studies have focused on more specific measurements, while in the Cardiovascular Health Cognition Study of Medicare recipients, the participants in the lowest quartile of arm span had increased risk of incident clinical AD [49]. Effects were not mediated by education, income or self-reported health.

Though most of these studies indicate that reduced body measurements may predispose to $\mathrm{AD}$, a few studies either qualify or disagree with these results. In 215 men and women aged 66-75 years from England whose head circumference had been recorded at birth and as adults, people who had a larger head circumference as an adult, but not at birth, were less likely to show decline over a 3.5year period in immediate and delayed recall on the Logical Memory test [50]. Although diagnosis of $\mathrm{AD}$ was not made in this study, impaired delayed recall is specifically associated with AD. Similarly, a study of 674 subjects with normal cognition, amnestic mild cognitive impairment or $\mathrm{AD}$ found that increased intracranial volume attenuated the impact of cortical atrophy from $\mathrm{AD}$ on cognition [51]. Though body measurements are presumably determined in early life, it is possible that growth in adolescence and young adulthood contributes to adult body measurements and the risk for AD. Finally, 3 other studies showed no association between intracranial volume measurements and clinical diagnosis or age of onset of AD [52-54].

Interactions with APOE genotype, gender and other factors may explain some of these discrepancies (although one study showed no interaction with genotype) [44]. Among a cohort of 1,859 Japanese Americans living in Washington, followed prospectively for 6 years, developmental risk factors were associated with incident $\mathrm{AD}$ in $A P O E 4$-positive individuals, whereas vascular risk factors were more important for APOE4-negative individuals [55]. In 59 incident cases of probable $\mathrm{AD}$ identified from 1,869 individuals, the combination of low head circumference and APOE4 strongly predicted earlier onset of $\mathrm{AD}[56]$.

Taken together, a few consistent and interesting findings emerge from the literature of early-life body growth and dementia. There appears to be an association between early life markers of childhood body growth (height, arm length, leg length, head circumference) and clinical diagnosis of AD in some studies and the effect of body growth on $\mathrm{AD}$ risk likely follows a critical-window model. This association appears partly independent of education but may interact with gender, APOE status and handedness. Importantly, the relationship between earlylife body growth and pathologically defined $\mathrm{AD}$ has not been demonstrated and will be an important area of further research. 


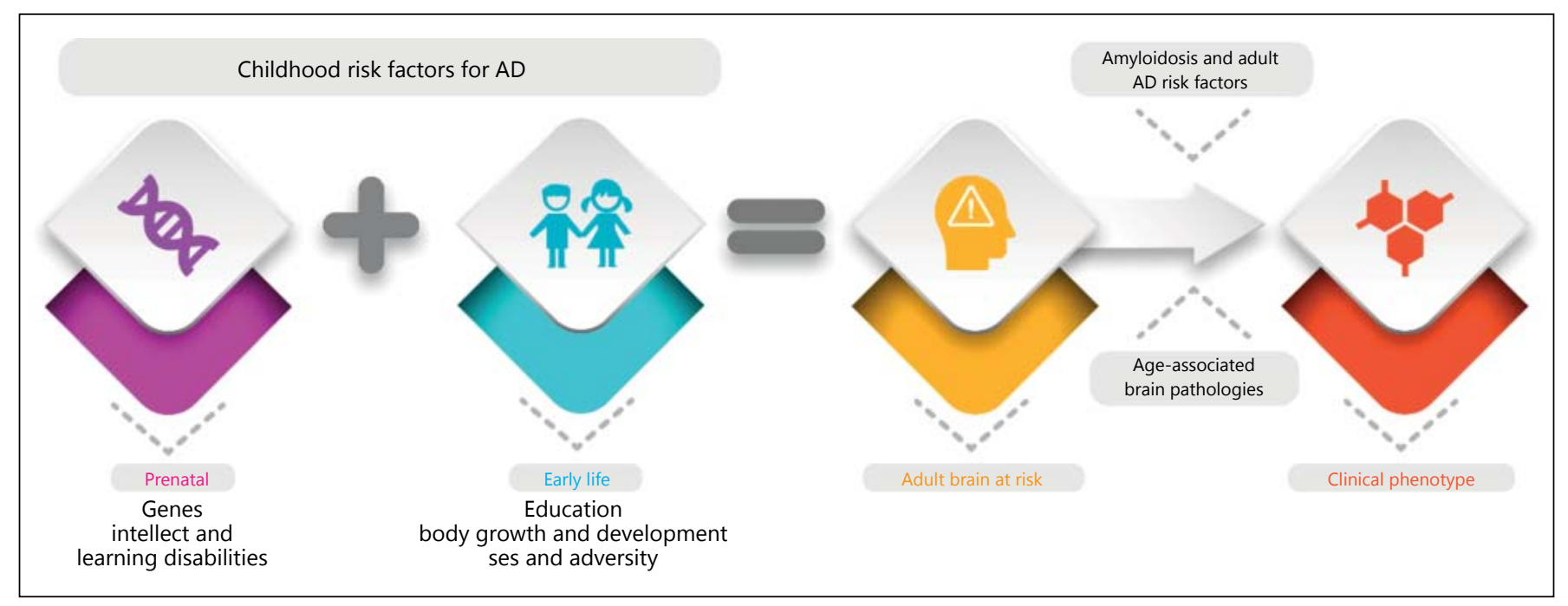

Fig. 3. Conceptual model of relationship between early-life risk factors and adult $\mathrm{AD}$ pathology. In this model, genetically and environmentally influenced childhood brain structure determines adult brain structure and vulnerability. Subsequently, cumulative age-related brain pathologies (including cerebrovascular disease,

\section{Childhood Adversity}

Childhood adversity includes abuse and neglect, parental mental illness, substance abuse, criminal behavior and domestic violence, as well as parental loss and divorce, childhood physical illness and family economic adversity. Although the negative effect of childhood adversity on adult cognition and brain structure is well-established [57], few studies have examined the relationship between exposure to childhood adversity and cognitive decline or dementia due to AD. Currently, only one study relates childhood adversity to clinical or pathological diagnosis of AD. In a population-based study of over 4,000 older subjects in Utah, adults with who had suffered maternal death from 11 to 17 years were twice as likely to develop AD [58]. Though it did not study AD specifically, the Israel Heart Disease cohort study similarly demonstrated that the risk for incident dementia (of any type) was increased in individuals who reported experiencing parental death in childhood as compared to parental death in adulthood, particularly for individuals who experienced the event at a younger age in childhood [59]. In contrast, one study showed different relationships between childhood adversity and cognitive decline in African Americans and Caucasian, over a follow-up of 16 years [60]. The effects of childhood adversity on $\mathrm{AD}$ may follow a latent exposure model: initial sequelae of childhood trauma, such as reduced hippocampal size, would synucleinopathy and TDP-43) and other adult risk factors influence when and whether neurodegeneration begins in the selectively vulnerable region. Interventions to address childhood risk factors for $\mathrm{AD}$ would work by influencing childhood brain development.

subsequently be exacerbated in the presence of late-life stressors and risk factors. Effects will likely depend upon the particular timing of the event during childhood.

\section{Discussion}

As shown in figure 3, several early-life factors have been associated with increased risk of clinical diagnosis of AD through their impact on adult brain structure. Table 1 shows the number of studies included in this review segregated by risk factor category. Below, we will briefly review the evidence and mechanistic model of risk of each of the early-life exposures that are summarized in table 2.

Genetics may influence AD risk by altering the developmental trajectories and ultimate adult connectivity of functional brain networks. As discussed above, these networks show structural and functional abnormalities as early as childhood, suggesting that their pathological trajectories may influence cognitive health long before the appearance of dementia. In addition, epigenetic modifications may play a significant role in $\mathrm{AD}$ pathology; recent studies in humans have identified multiple genes methylated in $\mathrm{AD}$ that are linked to $P T K 2 B$, a regulator of hippocampal synaptic function [91]. Consistent with the concept of selective vulnerability, in which the developmental history of a brain region determines the course of its later 
Table 2. Mechanistic models describing the effects of early-life risk factors on AD risk

\begin{tabular}{lll}
\hline Risk factor & Model & Mechanism \\
\hline Childhood SES & Trajectory & Gradual accrual of risk or protection over time \\
Body growth & Critical window & Timing-specific risk or protection \\
Intellect and learning disability & Latent & Initial factor unmasked by a later factor \\
Genetics & Trajectory & Initial factor determines later development \\
Childhood adversity & Latent & Initial factor unmasked by a later factor \\
\hline
\end{tabular}

degeneration, these modified functional networks will be particularly vulnerable to late-life neurodegeneration [92].

Developmental learning disabilities and low native intellect may act as latent risks for different phenotypic variants of neurodegenerative disease. Dyslexia is present in $7 \%$ of the population [87] and is thought to be caused by under-activity in the left temporal and occipital regions during reading and abnormal activation of the left inferior frontal gyrus [88-90]. In this review, we described 3 studies linking dyslexia to atypical neurodegenerative disease and proposed that dyslexia anatomically predisposes the brain to an atypical variant of $A D$ that presents as logopenic PPA. It remains to be seen whether other types of LD (e.g. dyscalculia) influence the anatomical involvement and clinical phenotype of neurodegenerative disease, and better imaging methods will be required to examine whether congenitally affected brain regions in people with specific LDs are indeed the first to be affected in late-life degeneration.

Evidence for an association between early-life SES and $\mathrm{AD}$ is equivocal, though multiple cross-sectional studies have shown significantly increased AD risk in groups with low childhood SES. Study of SES is particularly challenging because of its close relationship with educational opportunities. Early-life SES affects adult cognitive outcomes partly by influencing adult SES and education levels [61-66], while unfavorable SES is an independent risk factor for AD [67]. Biologically, early-life SES alters telomere attrition rates and hippocampal volumes [37, 68] and low childhood SES is a risk factor for stroke [69]. In addition, education increases cognitive and brain reserve; higher education has been associated with increased cortical thickness in the temporal lobe [70], as well as lower cerebrospinal fluid tau concentrations in patients with amnestic mild cognitive impairment [71]. Importantly, education is partially separable from other risk factors: though education may determine adult SES, low education is an independent risk factor for $\mathrm{AD}[72,73]$. The effects of childhood SES are consistent with a trajectory

Early Life Epidemiology of AD model as SES may determine the later educational, cognitive and neuroanatomical path of the individual and ultimately lead to the development of $\mathrm{AD}$.

The relationship between body measurements, physiologic variables like brain size and nutrition, and late-life $\mathrm{AD}$ are complex. Though this may be due to increased brain reserve [81] (and cognitive reserve), other causal mechanisms are likely at work. Small head size and susceptibility to $\mathrm{AD}$ may share genetic influences, or small head size may reflect environmental exposures that increase the risk of AD independently of brain size. Importantly, the critical window for nutrition is during pregnancy and the first 2 years of life [82], and chronic undernutrition affects about 165 million children worldwide (primarily in Sub-Saharan Africa and South Asia) [83]. Anthropomorphic measurements of body growth are thus markers of early nutritional status. Neurobiologically, undernutrition can delay the rate of cell division; myelination is especially vulnerable to even moderate undernourishment, and the resulting hypomyelination can permanently affect the brain even after nutritional restoration [84]. Metabolically, IGF-1 levels were recently related to incident $\mathrm{AD}$ [85] and may be altered by suboptimal nutrition and subsequent insulin resistance [86]. Further research on the mechanisms and reliability of anthropomorphic measurements as proxies for critical developmental windows on brain reserve and AD risk is necessary.

Effects of childhood adversity on brain and behavior are remarkably timing-specific [74], so a critical window model applies best. Exposure to childhood adversity is surprisingly common; $73 \%$ of respondents in one study reported exposure to at least one adversity [75]. One longitudinal study has shown a clear association between childhood adversity and AD, and others have linked adversity and all-cause dementia. The effects of adversity may be mediated by chronic stress, increased vulnerability to neurodegeneration, cellular senescence via shortened telomere length [76, 77], or ineffective coping strategies such as tobacco use and alcoholism $[69,78]$. Expo- 
sure to childhood adversities also increases the risk of heart disease, stroke and diabetes, all of which are risk factors for $\mathrm{AD}[79,80]$.

Several methodological challenges preclude our ability to draw clear associations between early life factors and AD risk. Almost all studies relied on clinical diagnosis of AD using NINDCDS/NINDS criteria rather than neuropathological diagnosis. These criteria only detect $81 \%$ of pathologically confirmed cases of $\mathrm{AD}$ and are only $70 \%$ specific [93] as $\mathrm{AD}$ dementia is associated with multiple underlying pathologies including amyloidopathy, cerebrovascular disease, synucleinopathy and TDP-43 [94]. Also, very few studies used an a priori approach to test mediating adult life mechanisms of early-life factors and instead relied on self-report and indirect measures. Few studies were prospective and survival bias was prominent because early-life factors may cause selective attrition of weaker individuals. Early-life factors may explain the poorly understood phenomenon of phenotypic heterogeneity in $\mathrm{AD}$. The typical, late-onset phenotype of $\mathrm{AD}$ begins with amnestic symptoms that correlate with neurofibrillary pathology in lateral entorhinal cortex. Atypical phenotypes of AD (PCA and logopenic PPA), begin with non-amnestic symptoms and neurofibrillary pathology in non-hippocampal structures [95]. The varying susceptibility of different brain networks to AD pathology in different individuals may relate to the concept of selective vulnerability, which posits that the brain networks that developed least optimally during early life are among the first to degenerate during later life [92]. Intriguingly, AD preferentially affects the evolutionarily newest regions of the human brain (higher order association cortex) [96] and the neurofibrillary neurodegeneration of $\mathrm{AD}$ seems to spread in reverse order to that of cortical myelination, beginning in the neurons which are the last to myelinate and the most poorly myelinated [97]. Because myelination is mostly finished by young adulthood, this may have implications for primary prevention.
There are myriad challenges for future investigation of the relationship between early-life factors and $\mathrm{AD}$ risk. The prevalence of childhood risk factors, particularly in children at genetic risk for $\mathrm{AD}$, requires more accurate measurement and interactions between exposures and genetic risk for AD remain unclear. Though some mechanisms by which early life factors influence late-life cognitive outcomes are partially understood and are discussed above, detailed molecular and anatomic pathophysiology has yet to be described. Timing effects, particularly during critical windows of brain development such as adolescence, and ongoing identification of gene candidates for learning disabilities represent particularly important opportunities for exploration. Finally, more epidemiological studies need to incorporate pathological end points as pathology can both confirm the clinical $\mathrm{AD}$ diagnosis and reveals much about the anatomical specificity of these myriad early-life exposures.

Careful epidemiology, linking well-measured exposures to pathologically defined dementia outcomes, may provide clues as to how the brain systematically degenerates during $\mathrm{AD}$ and other dementias. Ideally, a better understanding of the lifelong time-course of $\mathrm{AD}$ may lead to preventative interventions delivered during critical life stages; the availability of biomarkers to detect preclinical AD holds particular promise in this regard. Ultimately, identification of early life, causative risk factors for $\mathrm{AD}$, especially in at-risk individuals such as those with family history of dementia, will help reduce the global burden of disability from dementia.

\section{Acknowledgments}

Support included NIH/NIA grant 5T32NS007153 as well as the Leon Levy Foundation, the Taub Institute for Research on Alzheimer's Disease and the Aging Brain, the Henry P. Panasci Fund, and the Charles and Ann Lee Brown Fellowship Fund.

\section{References}

1 Lenroot RK, Giedd JN: Brain development in children and adolescents: insights from anatomical magnetic resonance imaging. Neurosci Biobehav Rev 2006;30:718-729.

2 Borenstein AR, Copenhaver CI, Mortimer JA: Early-life risk factors for Alzheimer disease. Alzheimer Dis Assoc Disord 2006;20:63-72.

3 Stern Y: Cognitive reserve in ageing and $\mathrm{Al}-$ zheimer's disease. Lancet Neurol 2012;11: 1006-1012.
4 Reiner O, Shmueli A, Sapir T: Neuronal migration and neurodegeneration: 2 sides of the same coin. Cereb Cortex 2009;19(suppl 1):i42-i48.

5 Miller DB, O'Callaghan JP: Do early-life insults contribute to the late-life development of Parkinson and Alzheimer diseases? Metabolism 2008;57(suppl 2):S44-S49.

6 Zawia NH, Basha MR: Environmental risk factors and the developmental basis for Al- zheimer's disease. Rev Neurosci 2005;16:325337.

7 Lahiri DK, Zawia NH, Greig NH, Sambamurti K, Maloney B: Early-life events may trigger biochemical pathways for Alzheimer's disease: the 'LEARn' model. Biogerontology 2008;9:375-379.

8 Whalley LJ, Dick FD, McNeill G: A life-course approach to the aetiology of late-onset dementias. Lancet Neurol 2006;5:87-96. 
9 Dean DC 3rd, Jerskey BA, Chen K, et al: Brain differences in infants at differential genetic risk for late-onset Alzheimer disease: a crosssectional imaging study. JAMA Neurol 2014; 71:11-22.

10 Felsky D, Szeszko P, Yu L, et al: The SORL1 gene and convergent neural risk for Alzheimer's disease across the human lifespan. Mol Psychiatry 2014;19:1125-1132.

11 Miller ZA, Mandelli ML, Rankin KP, et al: Handedness and language learning disability differentially distribute in progressive aphasia variants. Brain 2013;136:3461-3473.

12 Liu S, Jones RN, Glymour MM: Implications of lifecourse epidemiology for research on determinants of adult disease. Public Health Rev 2010;32:489-511.

13 Shaw P, Lerch JP, Pruessner JC, et al: Cortical morphology in children and adolescents with different apolipoprotein E gene polymorphisms: an observational study. Lancet Neurol 2007;6:494-500.

14 Lind J, Larsson A, Persson J, et al: Reduced hippocampal volume in non-demented carriers of the apolipoprotein E epsilon4: relation to chronological age and recognition memory. Neurosci Lett 2006;396:23-27.

15 Valla J, Yaari R, Wolf AB, et al: Reduced posterior cingulate mitochondrial activity in expired young adult carriers of the APOE $\varepsilon 4$ allele, the major late-onset Alzheimer's susceptibility gene. J Alzheimers Dis 2010;22: 307-313.

16 Bloss CS, Delis DC, Salmon DP, Bondi MW: Decreased cognition in children with risk factors for Alzheimer's disease. Biol Psychiatry 2008;64:904-906.

17 Wen Y, Miyashita A, Kitamura N, et al: SORL1 is genetically associated with neuropathologically characterized late-onset $\mathrm{Al}$ zheimer's disease. J Alzheimers Dis 2013;35: 387-394.

18 Bralten J, Arias-Vasquez A, Makkinje R, et al: Association of the Alzheimer's gene SORL1 with hippocampal volume in young, healthy adults. Am J Psychiatry 2011;168:1083-1089.

19 Kim DH, Yeo SH, Park JM, et al: Genetic markers for diagnosis and pathogenesis of Alzheimer's disease. Gene 2014;545:185-193.

20 Louvi A, Sisodia SS, Grove EA: Presenilin 1 in migration and morphogenesis in the central nervous system. Development 2004;131: 3093-3105.

$21 \mathrm{Xu} \mathrm{W}$, Tan L, Wang HF, et al: Education and risk of dementia: dose-response meta-analysis of prospective cohort studies. Mol Neurobiol 2015, Epub ahead of print.

22 Meng X, D'Arcy C: Education and dementia in the context of the cognitive reserve hypothesis: a systematic review with meta-analyses and qualitative analyses. PLoS One 2012; 7:e38268.

23 Mehta KM, Stewart AL, Langa KM, et al: 'Below average' self-assessed school performance and Alzheimer's disease in the aging, demographics, and memory study. Alzheimers Dement 2009;5:380-387.
24 Snowdon DA, Greiner LH, Markesbery WR: Linguistic ability in early life and the neuropathology of Alzheimer's disease and cerebrovascular disease. Findings from the Nun study. Ann N Y Acad Sci 2000;903:34-38.

25 Snowdon DA, Kemper SJ, Mortimer JA, Greiner LH, Wekstein DR, Markesbery WR: Linguistic ability in early life and cognitive function and Alzheimer's disease in late life. Findings from the Nun study. JAMA 1996; 275:528-532.

26 Rogalski E, Weintraub S, Mesulam MM: Are there susceptibility factors for primary progressive aphasia? Brain Lang 2013;127:135138.

27 Rogalski E, Johnson N, Weintraub S, Mesulam M: Increased frequency of learning disability in patients with primary progressive aphasia and their first-degree relatives. Arch Neurol 2008;65:244-248.

28 Sajjadi SA, Patterson K, Nestor PJ: Logopenic, mixed, or Alzheimer-related aphasia? Neurology 2014;82:1127-1131.

29 Rogalski EJ, Rademaker A, Wieneke C, Bigio EH, Weintraub S, Mesulam MM: Association between the prevalence of learning disabilities and primary progressive aphasia. JAMA Neurol 2014;71:1576-1577.

30 Seifan A, Assuras S, Huey ED, Mez J, Tsapanou A, Caccappolo E: Childhood learning disabilities and atypical dementia: a retrospective chart review. PLoS One 2015; 10:e0129919.

31 Cohen S, Janicki-Deverts D, Chen E, Matthews KA: Childhood socioeconomic status and adult health. Ann N Y Acad Sci 2010; 1186:37-55.

32 Hall KS, Gao S, Unverzagt FW, Hendrie HC: Low education and childhood rural residence: risk for Alzheimer's disease in African Americans. Neurology 2000;54:95-99.

33 Moceri VM, Kukull WA, Emanual I, et al: Using census data and birth certificates to reconstruct the early-life socioeconomic environment and the relation to the development of Alzheimer's disease. Epidemiology 2001;12: 383-389.

34 Moceri VM, Kukull WA, Emanuel I, van Belle G, Larson EB: Early-life risk factors and the development of Alzheimer's disease. Neurology 2000;54:415-420.

35 Everson-Rose SA, Mendes de Leon CF, Bienias JL, Wilson RS, Evans DA: Early life conditions and cognitive functioning in later life. Am J Epidemiol 2003;158:1083-1089.

36 Wilson RS, Scherr PA, Hoganson G, Bienias JL, Evans DA, Bennett DA: Early life socioeconomic status and late life risk of Alzheimer's disease. Neuroepidemiology 2005;25:814.

37 Staff RT, Murray AD, Ahearn TS, Mustafa N, Fox HC, Whalley LJ: Childhood socioeconomic status and adult brain size: childhood socioeconomic status influences adult hippocampal size. Ann Neurol 2012;71:653-660.

38 Negash S, Wilson RS, Leurgans SE, et al: Resilient brain aging: characterization of discor- dance between Alzheimer's disease pathology and cognition. Curr Alzheimer Res 2013;10: 844-851.

39 Brewster PW, Melrose RJ, Marquine MJ, et al: Life experience and demographic influences on cognitive function in older adults. Neuropsychology 2014;28:846-858.

40 Wadsworth ME, Hardy RJ, Paul AA, Marshall SF, Cole TJ: Leg and trunk length at 43 years in relation to childhood health, diet and family circumstances; evidence from the 1946 national birth cohort. Int J Epidemiol 2002;31: 383-390.

41 Kim JM, Stewart R, Shin IS, Yoon JS: Limb length and dementia in an older Korean population. J Neurol Neurosurg Psychiatry 2003; 74:427-432.

42 Jeong SK, Kim JM, Kweon SS, Shin MH, Seo MW, Kim YH: Does arm length indicate cognitive and functional reserve? Int J Geriatr Psychiatry 2005;20:406-412.

43 Schofield PW, Mosesson RE, Stern Y, Mayeux $\mathrm{R}$ : The age at onset of Alzheimer's disease and an intracranial area measurement. A relationship. Arch Neurol 1995;52:95-98.

44 Schofield PW, Logroscino G, Andrews HF, Albert S, Stern Y: An association between head circumference and Alzheimer's disease in a population-based study of aging and dementia. Neurology 1997;49:30-37.

45 Vladeanu M, Giuffrida O, Bourne VJ: Prenatal sex hormone exposure and risk of $\mathrm{Al}$ zheimer disease: a pilot study using the 2D:4D digit length ratio. Cogn Behav Neurol 2014; 27:102-106.

46 Luciano R, Barraco GM, Muraca M, et al: Biomarkers of Alzheimer disease, insulin resistance, and obesity in childhood. Pediatrics 2015;135:1074-1081.

47 Abbott RD, White LR, Ross GW, et al: Height as a marker of childhood development and late-life cognitive function: the HonoluluAsia aging study. Pediatrics 1998; 102:602609.

48 Beeri MS, Davidson M, Silverman JM, Noy S, Schmeidler J, Goldbourt U: Relationship between body height and dementia. Am J Geriatr Psychiatry 2005;13:116-123.

49 Huang TL, Carlson MC, Fitzpatrick AL, Kuller LH, Fried LP, Zandi PP: Knee height and arm span: a reflection of early life environment and risk of dementia. Neurology 2008;70:1818-1826.

50 Gale CR, Walton S, Martyn CN: Foetal and postnatal head growth and risk of cognitive decline in old age. Brain 2003;126:2273-2278.

51 Guo LH, Alexopoulos P, Wagenpfeil S, Kurz A, Perneczky R: Brain size and the compensation of Alzheimer's disease symptoms: a longitudinal cohort study. Alzheimers Dement 2013;9:580-586.

52 Graves AB, Mortimer JA, Larson EB, Wenzlow A, Bowen JD, McCormick WC: Head circumference as a measure of cognitive reserve. Association with severity of impairment in Alzheimer's disease. Br J Psychiatry 1996;169:86-92. 
53 Jenkins R, Fox NC, Rossor AM, Harvey RJ, Rossor $\mathrm{MN}$ : Intracranial volume and $\mathrm{Al}-$ zheimer disease: evidence against the cerebral reserve hypothesis. Arch Neurol 2000;57: 220-224.

54 Edland SD, Xu Y, Plevak M, et al: Total intracranial volume: normative values and lack of association with Alzheimer's disease. Neurology 2002;59:272-274.

55 Borenstein Graves A, Mortimer JA, Bowen $J D$, et al: Head circumference and incident Alzheimer's disease: modification by apolipoprotein E. Neurology 2001;57:1453-1460.

56 Borenstein AR, Wu Y, Mortimer JA, et al: Developmental and vascular risk factors for $\mathrm{Al}$ zheimer's disease. Neurobiol Aging 2005;26: 325-334.

57 Pechtel P, Pizzagalli DA: Effects of early life stress on cognitive and affective function: an integrated review of human literature. Psychopharmacology (Berl) 2011;214:55-70.

58 Norton MC, Smith KR, Østbye T, et al: Early parental death and remarriage of widowed parents as risk factors for Alzheimer disease: the Cache County study. Am J Geriatr Psychiatry 2011;19:814-824.

59 Ravona-Springer R, Beeri MS, Goldbourt U: Younger age at crisis following parental death in male children and adolescents is associated with higher risk for dementia at old age. Alzheimer Dis Assoc Disord 2012;26:68-73.

60 Barnes LL, Wilson RS, Everson-Rose SA Hayward MD, Evans DA, Mendes de Leon CF: Effects of early-life adversity on cognitive decline in older African Americans and whites. Neurology 2012;79:2321-2327.

61 Fors S, Lennartsson C, Lundberg O: Childhood living conditions, socioeconomic position in adulthood, and cognition in later life: exploring the associations. J Gerontol B Psychol Sci Soc Sci 2009;64:750-757.

62 Kobrosly RW, van Wijngaarden E, Galea S, et al: Socioeconomic position and cognitive function in the Seychelles: a life course analysis. Neuroepidemiology 2011;36:162-168.

63 Singh-Manoux A, Richards M, Marmot M: Socioeconomic position across the lifecourse: how does it relate to cognitive function in mid-life? Ann Epidemiol 2005;15:572-578.

64 Scazufca M, Menezes PR, Araya R, et al: Risk factors across the life course and dementia in a Brazilian population: results from the Sao Paulo ageing \& health study (SPAH). Int J Epidemiol 2008;37:879-890.

65 Kaplan GA, Turrell G, Lynch JW, Everson SA, Helkala EL, Salonen JT: Childhood socioeconomic position and cognitive function in adulthood. Int J Epidemiol 2001;30:256-263.

66 Luo Y, Waite LJ: The impact of childhood and adult SES on physical, mental, and cognitive well-being in later life. J Gerontol B Psychol Sci Soc Sci 2005;60:S93-S101.

67 Sattler C, Toro P, Schonknecht P, Schroder J: Cognitive activity, education and socioeconomic status as preventive factors for mild cognitive impairment and Alzheimer's disease. Psychiatry Res 2012;196:90-95.
68 Cherkas LF, Aviv A, Valdes AM, et al: The effects of social status on biological aging as measured by white-blood-cell telomere length. Aging Cell 2006;5:361-365.

69 Galobardes B, Smith GD, Lynch JW: Systematic review of the influence of childhood socioeconomic circumstances on risk for cardiovascular disease in adulthood. Ann Epidemiol 2006;16:91-104.

70 Liu Y, Julkunen V, Paajanen T, et al: Education increases reserve against Alzheimer's disease - evidence from structural MRI analysis. Neuroradiology 2012;54:929-938.

71 Rolstad S, Nordlund A, Eckerström C, et al: High education may offer protection against tauopathy in patients with mild cognitive impairment. J Alzheimers Dis 2010;21:221228.

72 Evans DA, Hebert LE, Beckett LA, et al: Education and other measures of socioeconomic status and risk of incident Alzheimer disease in a defined population of older persons. Arch Neurol 1997;54:1399-1405.

73 Karp A, Kåreholt I, Qiu C, Bellander T, Winblad B, Fratiglioni L: Relation of education and occupation-based socioeconomic status to incident Alzheimer's disease. Am J Epidemiol 2004;159:175-183.

74 Maercker A, Michael T, Fehm L, Becker ES, Margraf J: Age of traumatisation as a predictor of post-traumatic stress disorder or major depression in young women. Br J Psychiatry 2004;184:482-487.

75 McGurn B, Deary IJ, Starr JM: Childhood cognitive ability and risk of late-onset Alzheimer and vascular dementia. Neurology 2008;71:1051-1056.

76 Kume K, Kikukawa M, Hanyu H, et al: Telomere length shortening in patients with dementia with Lewy bodies. Eur J Neurol 2012. 19:905-910.

77 Honig LS, Kang MS, Schupf N, Lee JH, Mayeux R: Association of shorter leukocyte telomere repeat length with dementia and mortality. Arch Neurol 2012;69:1332-1339.

78 Kananen L, Surakka I, Pirkola S, et al: Childhood adversities are associated with shorter telomere length at adult age both in individuals with an anxiety disorder and controls. PLoS One 2010;5:e10826.

79 Scott KM, Von Korff M, Angermeyer MC, et al: Association of childhood adversities and early-onset mental disorders with adult-onset chronic physical conditions. Arch Gen Psychiatry 2011;68:838-844.

80 Goodwin RD, Stein MB: Association between childhood trauma and physical disorders among adults in the United States. Psychol Med 2004;34:509-520.

81 Rushton JP, Ankney CD: Brain size and $\operatorname{cog}$ nitive ability: correlations with age, sex, social class, and race. Psychon Bull Rev 1996;3:2136.
82 Victora CG, de Onis M, Hallal PC, Blössner M, Shrimpton R: Worldwide timing of growth faltering: revisiting implications for interventions. Pediatrics 2010;125:e473-e480.

83 UNICEF: Improving Child Nutrition: The Achievable Imperative for Global Progress, 2013.

84 Royland J, Klinkhachorn P, Konat G, Wiggins RC: How much undernourishment is required to retard brain myelin development. Neurochem Int 1992;21:269-274.

85 Westwood AJ, Beiser A, Decarli C, et al: Insulin-like growth factor-1 and risk of Alzheimer dementia and brain atrophy. Neurology 2014; 82:1613-1619.

86 Clark GM, Zamenhof S, Van Mathens E, Grauel L, Kruger L: The effect of prenatal malnutrition on dimensions of cerebral cortex. Brain Res 1973;54:397-402.

87 Peterson RL, Pennington BF: Developmental dyslexia. Lancet 2012;379:1997-2007.

88 Paulesu E, Démonet JF, Fazio F, et al: Dyslexia: cultural diversity and biological unity. Science 2001;291:2165-2167.

89 Guttorm TK, Leppänen PH, Tolvanen A, Lyytinen $\mathrm{H}$ : Event-related potentials in newborns with and without familial risk for dyslexia: principal component analysis reveals differences between the groups. J Neural Transm 2003;110:1059-1074.

90 Raschle NM, Chang M, Gaab N: Structural brain alterations associated with dyslexia predate reading onset. Neuroimage 2011;57: 742-749.

91 Lord J, Cruchaga C: The epigenetic landscape of Alzheimer's disease. Nat Neurosci 2014;17: 1138-1140.

92 Mesulam MM: Primary progressive aphasia and the language network: the $2013 \mathrm{H}$. Houston Merritt Lecture. Neurology 2013;81:456462

93 Blacker D, Albert MS, Bassett SS, Go RC, Harrell LE, Folstein MF: Reliability and validity of NINCDS-ADRDA criteria for Alzheimer's disease. The National Institute of Mental Health Genetics Initiative. Arch Neurol 1994; 51:1198-1204.

94 Josephs KA, Whitwell JL, Weigand SD, et al: TDP-43 is a key player in the clinical features associated with Alzheimer's disease. Acta Neuropathol 2014;127:811-824.

95 Janocko NJ, Brodersen KA, Soto-Ortolaza AI, et al: Neuropathologically defined subtypes of Alzheimer's disease differ significantly from neurofibrillary tangle-predominant dementia. Acta Neuropathol 2012;124:681-692.

96 Braak H, Del Tredici K: Evolutional aspects of Alzheimer's disease pathogenesis. J Alzheimers Dis 2013;33(suppl 1):S155-S161.

97 Braak H, Rüb U, Schultz C, Del Tredici K: Vulnerability of cortical neurons to Alzheimer's and Parkinson's diseases. J Alzheimers Dis 2006;9(3 suppl):35-44.

98 Luciano R, Barraco GM, Muraca M, et al: Biomarkers of Alzheimer disease, insulin resistance, and obesity in childhood. Pediatrics 2015;135:1074-1081. 